\title{
Assessing Static Lung Hyperinflation by Whole-Body Plethysmography, Helium Dilution, and Impulse Oscillometry System (IOS) in Patients with COPD
}

This article was published in the following Dove Press journal: International Journal of Chronic Obstructive Pulmonary Disease

\author{
Michela D'Ascanio (D) \\ Fausta Viccaro' \\ Noemi Calabrò (iD) \\ Giulio Guerrieri ${ }^{1}$ \\ Claudia Salvucci $\mathbb{D}^{\prime}$ \\ Dario Pizzirusso (iD) \\ Rita Mancini ${ }^{1}$ \\ Claudia De Vitis (D) \\ Aldo Pezzuto ${ }^{2}$ \\ Alberto Ricci ${ }^{\prime}{ }^{\prime}$ \\ 'Department of Clinical and Molecular \\ Medicine, Sant'Andrea Hospital, Sapienza \\ University of Rome, Rome, Italy; \\ ${ }^{2}$ Department of Cardiovascular and \\ Respiratory Sciences, Sant'Andrea \\ Hospital, Rome, Italy
}

Purpose: Lung hyperinflation is a feature of chronic obstructive pulmonary disease (COPD) and can determine pivotal consequence on symptoms, exercise tolerance and quality of life. Despite the relevance of assessing lung hyperinflation, there is still no single consensus as to what volume should be taken into account. We investigate which spirometric measurement is more reliable in assessing static lung hyperinflation and which is more related with impulse oscillometry system (IOS) measurements in COPD.

Patients and Methods: Fifty-five COPD patients were enrolled. TLC, RV and RV:TLC ratio were obtained both with helium and plethysmography techniques. IOS measurements (X5, Fres and R5-R20) were performed. Pearson and Spearman correlation determined the relationships between the functional parameters that evaluate static hyperinflation (RV: TLC, TLC, RV) and IOS measurements.

Results: As expected, we reported a statistically significant difference between these two techniques in terms of mean percentage values of TLC $(7.57 \pm 3.26 \mathrm{~L} ; \mathrm{p}=0.02)$ and RV $(15.24 \pm 7.51 \mathrm{~L} ; \mathrm{p}=0.04)$, while RV:TLC measured with the two methods was similar $(5.21 \pm$ $4.69 \% ; \mathrm{p}=0.27)$. The correlation analysis showed that IOS parameters, such as difference in resistance between $5 \mathrm{~Hz}$ and $20 \mathrm{~Hz}(\mathrm{R}(5-20))$ and resonant frequency (Fres), were positively correlated with RV:TLC ratio, while reactance at $5 \mathrm{~Hz}(\mathrm{X}(5))$ was negatively correlated with it. In particular, we pointed out a weak correlation between RV:TLC (\%) (Pleth) and R(5-20) $(\mathrm{r}=0.3, \mathrm{p}=0.04)$, Fres $(\mathrm{r}=0.3 ; \mathrm{p}=0.03)$, while X5 had a mild correlation with RV:TLC $(\%)(\mathrm{r}=$ $-0.5 ; \mathrm{p}<0.0001)$. Moreover, we noticed a strong relationship between RV:TLC $(\%)(\mathrm{He})$ and $\mathrm{X} 5(\mathrm{r}=-0.7 ; \mathrm{p}=0.0001)$ and a mild correlation between RV:TLC $(\%)(\mathrm{He})$ and Fres $(\mathrm{r}=0.4$; $\mathrm{p}=0.003)$. Between R5-R20 and RV:TLC, there was a weak correlation $(r=0.3 ; p=0.001)$. No correlation between TLC, RV (L,\%) (both helium and Pleth derived) and IOS parameters (R (5-20), X5, Fres) was found.

Conclusion: RV:TLC can represent the most reliable parameter in the assessment of hyperinflation, considering the absence of significant difference in its measurement between the two techniques. IOS provides supplementary information in the assessment of static hyperinflation.

Keywords: hyperinflation, COPD, IOS

\section{Introduction}

Chronic obstructive pulmonary disease (COPD) represents one of the leading causes of morbidity and mortality in the industrialized and developing countries. In 2014 and 2015, more than $6 \%$ of adults aged 40 years or older reported having been diagnosed with COPD. ${ }^{1}$
Correspondence: Michela D’Ascanio Via di Grottarossa 1035/I039, Roma 00189 , RM, Italy

Tel +390633776768

Email dascaniomichela87@gmail.com
International Journal of Chronic Obstructive Pulmonary Disease 2020:15 2583-2589

2583

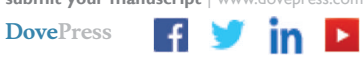

htp:/10i.org/10.214 
It is a respiratory disease characterized by progressive airflow obstruction, not fully reversible. In many cases, airflow obstruction is associated with hyperinflation, which leads to a deterioration in the quality of life and exercise capacity. ${ }^{2}$

Hyperinflation could be determined by reduced lung elastic recoil combined with expiratory flow limitation and it can be distinguished in static and dynamic.,

The mechanisms and pathophysiological consequences of hyperinflation are complex and not fully elucidated. In conditions of bronchoconstriction, the hyperinflation is apparently determined mainly by dynamic factors. The most important of these is the increased airway resistance with prolonged mechanical expiratory time constants and, thus, slow and incomplete lung emptying. ${ }^{5}$

Dynamic lung Hyperinflation is the main cause of poor exercise tolerance in COPD patients. ${ }^{6}$

CPET and the evaluation of the inspiratory constraints and ventilatory inefficiency have an important role in the evaluation of the exertional dyspnea. ${ }^{7}$

There have been several reports demonstrating that, besides COPD patients who dynamically hyperinflate during exercise (hyperinflators), there are also patients who do not hyperinflate during exercise (non-hyperinflators). In hyperinflators, during the exercise, important abnormalities regarding respiratory mechanics and cardiac output occur. For these reasons, some authors showed that breathe Heliox ( $79 \%$ helium- $21 \%$ oxygen) induce reduction of dynamic lung hyperinflation and is associated with consistent improvement in indices of cardio-circulatory function., ${ }^{8,9}$

Established the implication of dynamic hyperinflation in COPD physiopathology, through our study we want to focus on static hyperinflation.

Static hyperinflation, defined as an increased volume of air remaining in the lung at the end of spontaneous expirations, is present when resting functional residual capacity (FRC) or end expiratory lung volume (EELV) are increased above normal. It is caused by entrapment of air during expiration. ${ }^{10}$

Measurement of expiratory flow is basically used for the diagnosis and staging of COPD, while, to quantify static hyperinflation, lung volumes parameters such as Residual Volume (RV), Total Lung Capacity (TLC) and RV:TLC ratio (RV:TLC) $)^{3}$ are needed.

Despite the clinical relevance of assessing static hyperinflation, at the moment, there is no consensus on the parameters of severity to be considered, volume compartment to refer on and the method of choice. ${ }^{11}$ It is known that hyperinflation is determinate from airway obstruction and reduced lung elastic recoil but it is not well explored how to assess the contribution of them.

Impulse oscillometry system (IOS) is a variant of forced oscillation technique, described by Dubois over 50 years ago, which permits passive measurement of lung mechanics. It represents a useful tool for the study of small airway obstruction and is more sensitive than spirometry for peripheral airway disease. ${ }^{12}$

Kolsum et al showed that IOS reactance measurement well correlate with some measurement of hyperinflation (like TLC, RV and IC) ${ }^{13}$ but they did not explore the relation with RV:TLC.

We investigate which spirometric measurement is more reliable in assessing static lung hyperinflation and which is more related with IOS measurements in COPD.

\section{Patients and Methods}

\section{Subjects}

Our study was conducted at the Sant'Andrea Hospital in Rome, in a period of about one year from January 2019 to January 2020. Patients' characteristics are described in Table 1.

A progressive enrollment of patients was conducted, and all patients diagnosed with COPD (according to the GOLD 2019 guidelines) who had access to outpatient clinic in our Hospital during the period of the study were considered. These included those who had the following characteristics: (a) FEV1/FVC ratio $<0.7$ after bronchodilation; (b) no acute exacerbation during previous 4 weeks; (c) stop the medications, which may influence pulmonary function testing for at least 24 hours; d) good ability to perform spirometry.

Table I Subject Characteristics

\begin{tabular}{|l|l|}
\hline Subjects (n.55) & Mean \pm SD \\
\hline Age $(\mathrm{yrs})$ & $69.5 \pm 8.9$ \\
Female/male & $20 / 35$ \\
$\mathrm{BMI}\left(\mathrm{kg} / \mathrm{m}^{2}\right)$ & $26.99 \pm 5.31$ \\
CAT & $13.79 \pm 5.46$ \\
mMRC & $1.73 \pm 0.99$ \\
FEVI $(\%$, predicted) & $61.96 \pm 20.47$ \\
R5 (cmH2O L s) & $6.49 \pm 2.84$ \\
R20 (cmH2O L s) & $3.86 \pm 1.24$ \\
X $5(\mathrm{cmH} 2 \mathrm{O} \mathrm{L} \mathrm{s})$ & $-2.36 \pm 1.25$ \\
Fres $(\mathrm{Hz})$ & $18.67 \pm 9.08$ \\
\hline
\end{tabular}

Abbreviations: BMI, body mass index; CAT, COPD assessment test; mMRC, modified Medical Research Council; FEVI, forced expiratory volume. 
The study protocol was approved by the Ethics Committee for the Province of Rome, Italy (5078_2018) and conducted in accordance with good clinical practices and the Declaration of Helsinki. All enrolled patients gave their informed consent.

\section{Pulmonary Function Tests}

In order to collect respiratory function parameters, both gas helium dilution technique and whole-body plethysmography were used. All tests were performed post bronchodilatator.

For the quality of FVC and $\mathrm{FEV}_{1}$ measurements, the American Thoracic Society/European Respiratory Society test criteria for acceptability and repeatability were respected $;{ }^{14}$ from each spirometry and lung volume at least 3 measurements were taken to assure reproducibility.

Pulmonary function tests (PFTs) were performed using the Master Screen Body (Jaeger, Hoechberg, Germany) equipped with the software Lab Manager V5.32.0 (CareFusion, Hoechberg, Germany).

\section{Helium Dilution}

The helium dilution method measures the FRC by a closed circuit method (MS-PFT Jager).

After obtaining helium equilibrium, the patient was asked to perform an expiratory reserve volume (ERV), an inspiratory capacity (IC) and finally a vital capacity (VC) maneuver. TLC was calculated by adding the mean value of inspiratory capacity to FRC.

\section{Body Plethysmography}

The patient, placed in the box, started breathing through a mouthpiece connected to the outside, allowing to record the vital capacity (VC). After that, the shutter was closed and the patient continued to breath against the closed shutter (at a rate $<1$ Hertz), obtaining functional residual capacity (FRC), total lung capacity (TLC), residual volume (RV).

\section{Impulse Oscillometry System}

The pulmonary resistance and reactance were measured using IOS (MasterScreen IOS, Viasys GmbH, Hoechberg, Germany). The device consists of a loudspeaker that generates pressure oscillations composed of multiple frequencies, which are superimposed during $30 \mathrm{~s}$ of normal tidal breathing. This allows the assessment of resistance and reactance at several frequencies simultaneously, ranging from 5 to $35 \mathrm{~Hz}$. Subjects sat upright, had a nose clip and firmly supported their cheeks with their hands. A minimum of three trials were performed.

The difference in resistance between $5 \mathrm{~Hz}$ and $20 \mathrm{~Hz}$ $(\mathrm{R}(5-20))$, reactance at $5 \mathrm{~Hz}(\mathrm{X} 5)$ and resonant frequency (Fres) were recorded.

R (5-20) was used as a surrogate for the frequency dependence of respiratory resistance, which increases with increasing inhomogeneity of peripheral airways.

Reactance (X5, Fres) can be considered as the out of phase component of respiratory impedance (with flow, but not volume), reflecting the balance between inertial and elastic properties of distensible airways. Typically, this is measured at $5 \mathrm{~Hz}$ (X5) and by means of resonant frequency (Fres), the latter representing the point at which opposing inertial and capacitive components cancel each other out. ${ }^{6}$

\section{Statistical Analysis}

Dichotomous variables were presented as proportions and continuous variables as mean $\pm \mathrm{SD}$. The normality of data was checked. The comparison between volumes by the two methods was done by paired $\mathrm{t}$-student. Pearson correlation or Spearman correlation was applied to determine the relationships between IOS measurements and pulmonary function measurements.

A two-tailed $\mathrm{P}<0.05$ was considered to indicate statistical significance. Analysis was performed using GraphPad Prism software (version 8.4.1) (GraphPad Software, San Diego, CA).

\section{Results}

The anthropometric and functional characteristics of the 55 analyzed patients are described in Table 1. Among all the patients, 22 patients (40\%) had a FEV1 $<50 \%$ and 33 patients $(60 \%)$ had a FEV1 $\geq 50 \%$.

\section{Differences Between Measures Derived from Helium Dilution Technique $(\mathrm{He})$ and Plethysmography (Pleth)}

As expected, TLC and RV values were higher in plethysmographic technique measurements. We reported a statistically significant difference between these two techniques in terms of mean predicted percentage values of TLC $(7.57 \pm 3.26 \mathrm{~L} ; \mathrm{p}=0.02)$ and RV $(15.24 \pm 7.51 \mathrm{~L}$; $\mathrm{p}=0.04)$, this difference is greater the smaller is FEV1. No differences were found between the two methods for RV: TLC $(5.21 \pm 4.69 \%$; $p=0.26)$ (Table 2, Figure 1). RV:TLC 
Table 2 Lung Volumes Measured Both with Pleth and He. Differences Between Each Measurement are Reported

\begin{tabular}{|l|l|l|l|}
\hline & Pleth & He & $\Delta, \mathbf{P}$ value \\
\hline TLC (L) & $6.23 \pm 1.53$ & $5.89 \pm 1.39$ & $0.33 \pm 0.28, p=0.24$ \\
TLC (\%) & $107.91 \pm 17.99$ & $100.3 \pm 15.49$ & $7.57 \pm 3.26 ; p=0.02 *$ \\
RV (L) & $3.42 \pm 1.12$ & $3.01 \pm 0.76$ & $0.43+0.18 ; p=0.02$ \\
RV (\%) & $143.02 \pm 44.82$ & $128.0 \pm 31.53$ & $15.24 \pm 7.51 ; p=0.04 *$ \\
RV:TLC ratio & $53.41 \pm 11.83$ & $50.77 \pm 89.04$ & $2.77 \pm 2.16 ; p=0.20$ \\
RV:TLC ratio (\%) & $126.1 \pm 22.62$ & $121 \pm 22.45$ & $5.21 \pm 4.69 ; p=0.37$ \\
\hline
\end{tabular}

Note: *Statistically significant.

Abbreviations: He, helium dilution; Pleth, plethysmography; TLC, total lung capacity; RV, residual volume.

is inversely associated with airway obstruction measured with FEV1\% predicted $(r=-0.77 ; \mathrm{p}<0.0001)$.

\section{IOS Measurements and Correlation with Pleth and He Derived Parameters}

The correlation analysis showed that IOS parameters, such as difference in resistance between $5 \mathrm{~Hz}$ and $20 \mathrm{~Hz}(\mathrm{R}$ (5-20)) and resonant frequency (Fres), were positively correlated with RV:TLC ratio, while reactance at $5 \mathrm{~Hz}$ (X(5)) was negatively correlated with it (Figure 2).

In particular we pointed out a weak correlation between RV:TLC (\%) (Pleth) and $\mathrm{R}(5-20) \quad(\mathrm{r}=0.3$, $\mathrm{p}=0.04)$, Fres $(\mathrm{r}=0.3 ; \mathrm{p}=0.03)$, while $\mathrm{X} 5$ had a mild correlation with RV:TLC (\%) $(\mathrm{r}=-0.5 ; \mathrm{p}<0.0001)$. Moreover, we noticed a strong relationship between RV:TLC (\%)(He) and $\mathrm{X} 5(\mathrm{r}=-0.7 ; \mathrm{p}=0.0001)$ and a mild correlation between RV:TLC (\%) $(\mathrm{He})$ and Fres $(\mathrm{r}=0.4 ; \mathrm{p}=0.003)$

Between R(5-20) and RV:TLC (both helium and Pleth derived) there was a weak correlation $(\mathrm{r}=0.3 ; \mathrm{p}=0.001)$. No correlation between TLC, RV (L,\%) (both helium and

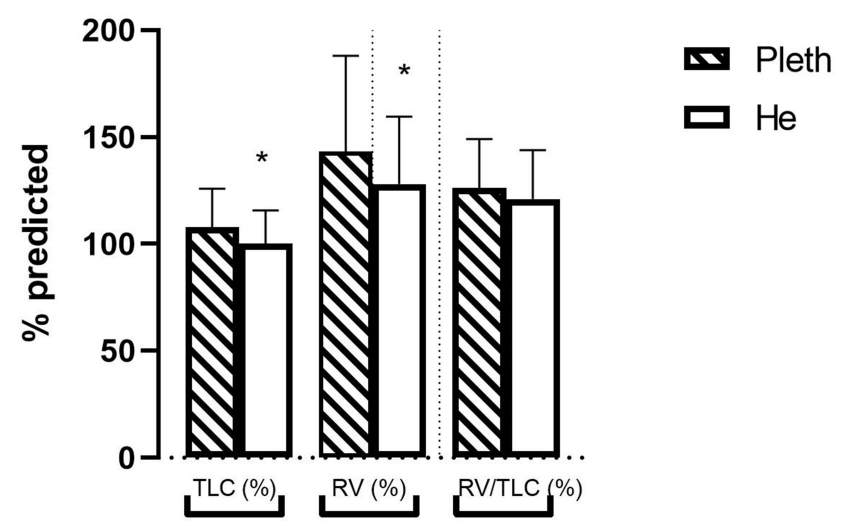

Figure I Differences among TLC, RV and RV/TLC ratio measured both with helium dilution $(\mathrm{He})$ and plethysmography (Pleth). *Statistically significant difference between these two techniques in terms of mean predicted percentage values of TLC and RV $(\mathrm{p}<0.05)$.
Pleth derived) and IOS parameters (R(5-20), X5, Fres) was found.

\section{Discussion}

Our study showed how RV:TLC is the most reliable and reproducible parameter to assess static hyperinflation, due to the absence of significant difference in its measurement between the two spirometric techniques. Moreover, RV: TLC has a significant correlation with IOS measurements.

Lung hyperinflation (LH) usually occurs in the natural history of COPD, due to the reduction of lung elastic recoil and increased resistance, contributing to develop exertional dyspnoea and exercise limitation. ${ }^{2}$

Conventionally LH is defined as TLC $>120 \%$ of the predicted value; even RV and RV:TLC above the upper limits of natural variability are considered index of $\mathrm{LH}^{3}$

Smith et al suggest that not all the functional parameters used to describe the hyperinflation have the same meaning: they hypothesize that RV and RV:TLC would be associated with small airways disease, while FRC, TLC and IC/TLC would be associated with emphysema. ${ }^{15}$

Some studies suggest that Pleth derived TLC could overestimate the volume, especially in cases of severe obstruction, ${ }^{16}$ while for others, Helium underestimates TLC because, in case of air trapping, it is difficult for the gas to reach all the lung areas. ${ }^{16,17}$

The novelty of our study is to show the reliability of RV:TLC due to its low variability in the measurements conduct with the two different methods.

Few studies have pointed out the importance of taking into account RV:TLC as a measurement representative of lung hyperinflation even if it represents a good prognostic factor of mortality and exacerbations in COPD patients. ${ }^{18,19}$

Zeng et al showed how, in smoker patient with a normal spirometry, the alteration of RV:TLC ratio could be predictive of a future COPD and could lead to an early diagnosis of the disease. $^{20}$ 
A
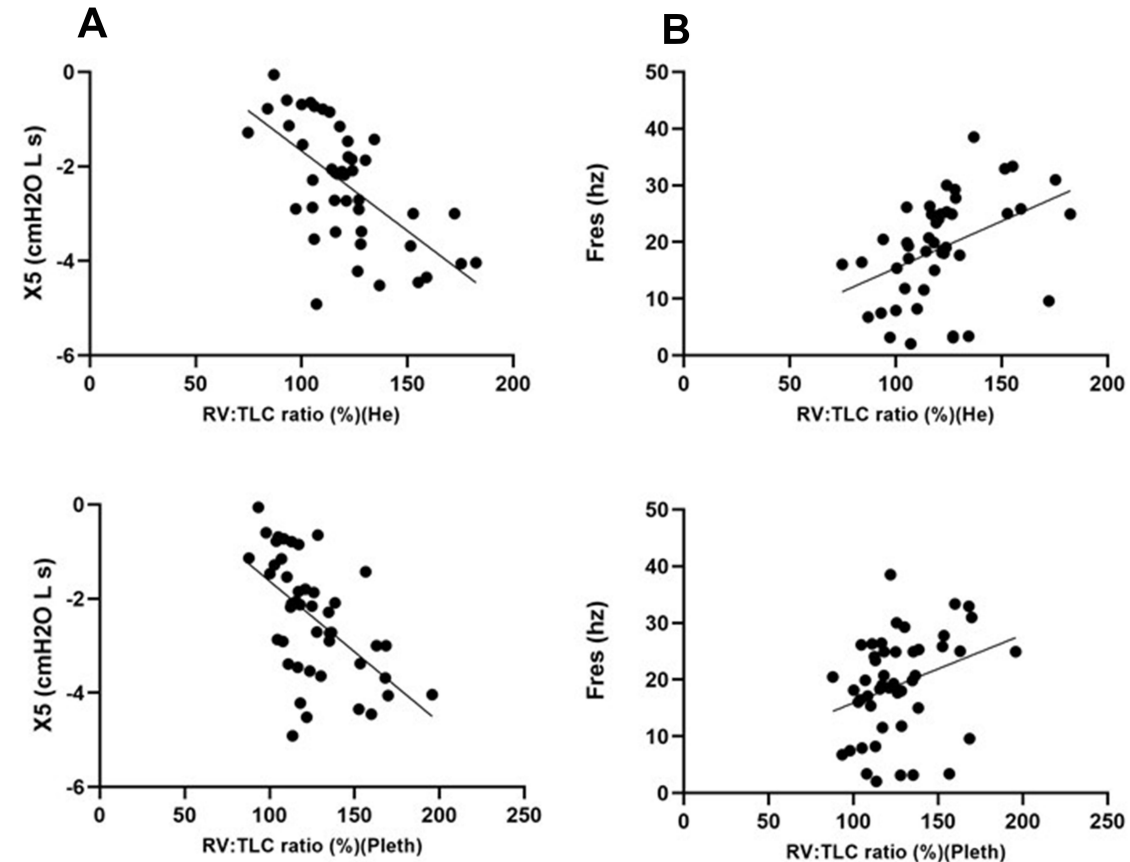

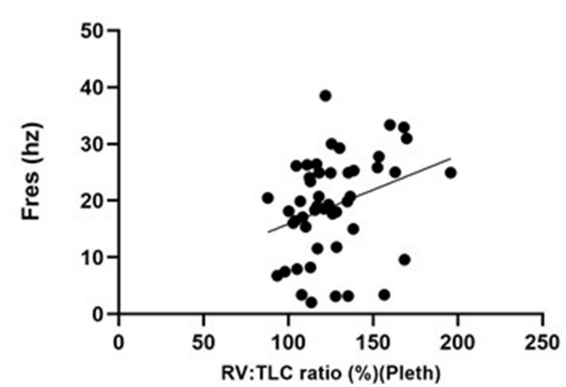

C
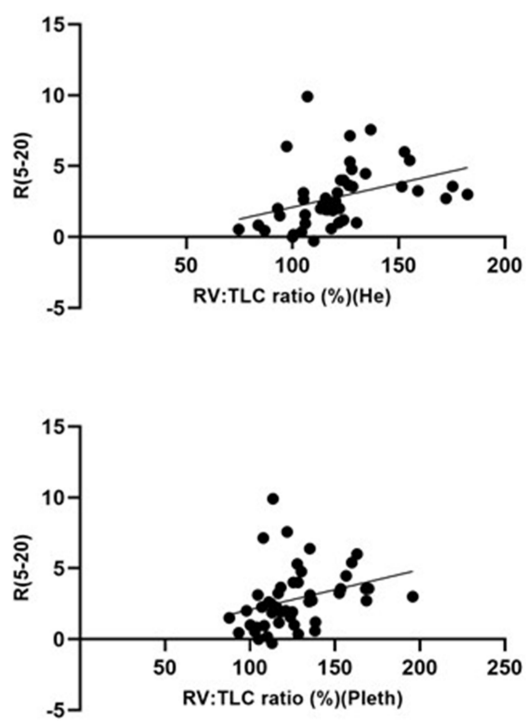

Figure 2 (A) Relationship between $\mathrm{X} 5(\mathrm{cmH} 20 \mathrm{~L} \mathrm{~s}$ ) and RV/TLC ratio (\%) (both He and Pleth derived). (B) Relationship between Fres (Hz) and RV:TLC ratio (\%) (both He and Pleth derived). (C) Relationship between R(5-20) and RV:TLC ratio (\%) (both He and Pleth derived).

Our results evidenced the strict relationship between RV:TLC and IOS measurements.

Kolsum et al had demonstrated that respiratory reactance measurement (X5 and FRes) is closely associated with more traditional measurement of pulmonary function in COPD patients. They explored the correlation between IOS reactance measurement and lung volume as TLC, RV and IC. ${ }^{13}$

Our results evidenced that X5 and Fres have no correlation with RV or TLC measured with $\mathrm{He}$ or Pleth, but correlate with RV:TLC showing a link between reactance measurements and hyperinflation.

The importance of our study is also to highlight the moderate correlation between RV:TLC as a measure of hyperinflation and peripheral airway resistance, well represented by R(5-20) measured by IOS. ${ }^{21}$ According to Singh et al, there is a vicious circle, between SAD (Small Airway Disease) and emphysema causing hyperinflation. ${ }^{22}$

For the important clinical implications of static hyperinflation and the weight that determines on COPD progression, there are many practical issues that need to be considered when deciding which pulmonary function measurement will provide the best method of assessing hyperinflation.

Our results show the importance of RV:TLC in assessing hyperinflation, regardless of the method used.
Due to the correlation with IOS measurements, we can use them as integrative parameters in global evaluation of COPD patient. This would allow IOS measurements to be compared to changes in RV:TLC as well as other well recognized pulmonary function parameters that assess hyperinflation.

IOS does not require a difficult performance by patients, but only tidal breathing, so it can be performed patients who are not compliant in performing spirometry correctly.

Based on our results, it would be useful for the future not only to use FEV1 to evaluate COPD patient but also RV:TLC. It will be able to provide information on the evolution and therapeutic response of the disease.

The RV:TLC ratio could also be used in the evaluation of patients with normal FEV1/FVC, but at risk of developing COPD, in order to perform early diagnosis and closer monitoring. ${ }^{23}$

The link between RV:TLC and the IOS measurements appear interesting, so that they can be used as a supplementary system in the overall assessment of static hyperinflation. In non-compliant patients, it can be used individually to make an estimate of hyperinflation although more studies are needed.

However, the ease of use of IOS and the sensitivity of this technique to measure the effects of therapeutic 
interventions in COPD patients ${ }^{9}$ should provide a sound basis for the increased use of this method in clinical practice.

Our study presents some limitations: the low sample although the study has good power and the absence of a follow-up that would allow us to understand the usefulness of RV:TLC as a parameter of pathology progression.

\section{Conclusion}

RV:TLC can represent the most reliable parameter in the assessment of hyperinflation, considering the absence of significant difference in its measurement between the two techniques. IOS provides supplementary information in the assessment of static hyperinflation.

\section{Abbreviations}

COPD, Chronic obstructive pulmonary disease; Pleth, Whole-body plethysmography; He, helium dilution; TLC, total lung capacity; RV, residual volume; LH, lung hyperinflation; FRC, functional residual capacity; FEV1, Forced Expiratory Volume; SAD, small airway disease.

\section{Data Sharing Statement}

The data that support the findings of this study are available from the corresponding author upon reasonable request.

\section{Consent for Publication}

All enrolled patients gave their informed consent.

\section{Acknowledgments}

We thank A. Piraino (MD) for assistance with for comments that greatly improved the manuscript.

\section{Author Contributions}

All authors contributed to data analysis, drafting or revising the article, have agreed on the journal to which the article will be submitted, gave final approval of the version to be published, and agree to be accountable for all aspects of the work.

\section{Funding}

The authors received no financial support for the research, authorship, and/or publication of this article.

\section{Disclosure}

The authors declare that they have no conflict of interest.

\section{References}

1. Biener AI, Decker SL, Rohde F. Prevalence and treatment of Chronic Obstructive Pulmonary Disease (COPD) in the United States. JAMA. 2019;322(7):602. doi:10.1001/jama.2019.10241

2. Rossi A, Aisanov Z, Avdeev S, et al. Mechanisms, assessment and therapeutic implications of lung hyperinflation in COPD. Respir Med. 2015;109(7):785-802. doi:10.1016/j.rmed.2015.03.010

3. O'Donnell DE, Laveneziana P. Physiology and consequences of lung hyperinflation in COPD. Eur Respir Rev. 2006;15(100):61-67. doi:10.1183/09059180.00010002

4. Gagnon P, Guenette JA, Langer D, et al. Pathogenesis of hyperinflation in chronic obstructive pulmonary disease. Int $J$ Chron Obstruct Pulmon Dis. 2014;9:187-201. doi:10.2147/COPD.S38934

5. Er J, Demedts M. Prosthodont [Editorial].

6. Lipworth BJ, Jabbal S. What can we learn about COPD from impulse oscillometry? Respir Med. 2018;139:106-109. doi:10.1016/j. rmed.2018.05.004

7. Neder JA, Berton DC, Marillier M, Bernard A-C, De ON. The role of evaluating inspiratory constraints and ventilatory inefficiency in the investigation of dyspnea of unclear etiology. Respir Med. 2019;158:6-13. doi:10.1016/j.rmed.2019.09.007

8. Louvaris Z, Zakynthinos S, Aliverti A, et al. Heliox increases quadriceps muscle oxygen delivery during exercise in COPD patients with and without dynamic hyperinflation. J Appl Physiol (1985). 2012;113 (7):1012-1023. doi:10.1152/japplphysiol.00481.2012

9. Laveneziana P, Valli G, Onorati P, Paoletti P, Ferrazza AM, Palange P. Effect of heliox on heart rate kinetics and dynamic hyperinflation during high-intensity exercise in COPD. Eur J Appl Physiol. 2011;111(2):225-234. doi:10.1007/s00421-010-1643-z

10. van Geffen WH, Kerstjens HA. Static and dynamic hyperinflation during severe acute exacerbations of chronic obstructive pulmonary disease. Int J Chron Obstruct Pulmon Dis. 2018;13:1269-1277. doi:10.2147/COPD.S154878

11. Pellegrino R, Viegi G, Brusasco V, et al. Interpretative strategies for lung function tests. Eur Respir J. 2005;26(5):948-968. doi:10.1183/ 09031936.05.00035205

12. Desiraju K, Agrawal A. Impulse oscillometry: the state-of-art for lung function testing. Lung India. 2016;33(4):410-416. doi:10.4103/ 0970-2113.184875

13. Kolsum U, Borrill Z, Roy K, et al. Impulse oscillometry in COPD: identification of measurements related to airway obstruction, airway conductance and lung volumes. Respir Med. 2009;103(1):136-143. doi:10.1016/j.rmed.2008.07.014

14. Miller MR, Hankinson J, Brusasco V, et al. Standardisation of spirometry. Eur Respir J. 2005;26(2):319-338. doi:10.1183/ 09031936.05.00034805

15. Smith BM, Hoffman EA, Basner RC, Kawut SM, Kalhan R, Barr RG. Not all measures of hyperinflation are created equal. Chest. 2014;145(6):1305-1315. doi:10.1378/chest.13-1884

16. Andersson LG, Ringqvist I, Walker A. Total lung capacity measured by body plethysmography and by the helium dilution method. A comparative study in different patient groups. Clin Physiol. 1988;8(2):113-119. doi:10.1111/j.1475-097X.1988.tb00199.x

17. Dahlqvist M, Hedenstierna G. Lung volumes measured by helium dilution and by body plethysmography with mouth and oesophageal pressures: a comparative study in patients with lung disease. Clin Physiol Oxf Engl. 1985;5(2):179-187. doi:10.1111/j.1475-097x.1985. tb00594.x

18. Kim YW, Lee C-H, Hwang H-G, et al. Resting hyperinflation and emphysema on the clinical course of COPD. Sci Rep. 2019;9(1):1-8. doi:10.1038/s41598-019-40411-1

19. Shin TR, Oh Y-M, Park JH, et al. The prognostic value of residual volume/total lung capacity in patients with chronic obstructive pulmonary disease. J Korean Med Sci. 2015;30(10):1459-1465. doi: $10.3346 / \mathrm{jkms} .2015 .30 .10 .1459$ 
20. Zeng S, Tham A, Bos B, Jin J, Giang B, Arjomandi M. Lung volume indices predict morbidity in smokers with preserved spirometry. Thorax. 2019;74(2):114-124. doi:10.1136/thoraxjnl-2018-211881

21. Brashier B, Salvi S. Measuring lung function using sound waves: role of the forced oscillation technique and impulse oscillometry system. Breathe. 2015;11(1):57-65. doi:10.1183/20734735.020514
22. Singh D. Small airway disease in patients with chronic obstructive pulmonary disease. Tuberc Respir Dis. 2017;80(4):317-324. doi:10.4046/trd.2017.0080

23. Elbehairy AF, Guenette JA, Faisal A, et al. Mechanisms of exertional dyspnoea in symptomatic smokers without COPD. Eur Respir J. 2016;48(3):694-705. doi:10.1183/13993003.00077-2016

\section{Publish your work in this journal}

The International Journal of COPD is an international, peer-reviewed journal of therapeutics and pharmacology focusing on concise rapid reporting of clinical studies and reviews in COPD. Special focus is given to the pathophysiological processes underlying the disease, intervention programs, patient focused education, and self management protocols. This journal is indexed on PubMed Central, MedLine and CAS. The manuscript management system is completely online and includes a very quick and fair peer-review system, which is all easy to use. Visit http://www.dovepress.com/testimonials.php to read real quotes from published authors.

Submit your manuscript here: https://www.dovepress.com/international-journal-of-chronic-obstructive-pulmonary-disease-journal 